\title{
CARACTERIZAÇÃO E ESTRUTURAÇÃO DA EDUCAÇÃO DE JOVENS E ADULTOS NO PLANO MUNICIPAL DE EDUCAÇÃO 2015 - 2024 DE DIAS D’ÁVILA (BA)
}

\author{
ASSUNÇÃO - PARAGUAI
}

2020

\section{CARACTERIZAÇÃO E ESTRUTURAÇÃO DA EDUCAÇÃO DE JOVENS E ADULTOS NO PLANO MUNICIPAL DE EDUCAÇÃO 2015 - 2024 DE DIAS D’ÁVILA (BA)}

\author{
Matos, Verenilda Nascimento.
}

Luciana chaves Santos Pereira.

\section{RESUMO}

O objetivo deste trabalho é compreender as políticas públicas para a Educação de Jovens caracterização e estruturação da educação de jovens e adultos no plano municipal de educação 2015 - 2024 de Dias D’ávila (BA)no período de 2012 a 2015 . Tratou-se de uma revisão de literatura de caráter bibliográfico descritivo. Gil (2004, p.137) descreve a revisão de literatura como sendo uma ação sobre material já produzido. As publicações encontradas foram ordenadas como pesquisa e de revisão e, posteriormente, categorizadas. Historicamente a Educação de Adultos foi marcada pelo objetivo de erradicar o analfabetismo, que era visto como causa e não como efeito da situação econômica, social e cultural do país. Analisa ainda abordagem conferida à EJA nos documentos preparatório e final da Conferência Nacional de Educação (CONAE) e indica desafios prioritários desse campo educativo a serem enfrentados pelo novo PNE 2011-2020 nos âmbitos das concepções político-pedagógicas, do financiamento, da formação e profissionalização dos educadores e do regime de colaboração entre as esferas de governo.

Palavras-chaves: Educação de jovens e adultos. Planejamento educacional. Políticas educacionais. 


\begin{abstract}
The objective of this work is to understand the public policies for Youth Education characterization and structuring of youth and adult education in the municipal education plan 2015 - 2024 of Dias D'ávila (BA) in the period from 2012 to 2015. It was a literature review of a descriptive bibliographic character. Gil (2004, p.137) describes the literature review as being an action on material already produced. The publications found were ordered as research and review and later categorized. Historically, Adult Education was marked by the objective of eradicating illiteracy, which was seen as a cause and not as an effect of the country's economic, social and cultural situation. It also analyzes the approach given to EJA in the preparatory and fina documents of the National Education Conference (CONAE) and indicates priority challenges in this educational field to be faced by the new PNE 20112020 in the areas of political-pedagogical concepts, financing, training and professionalization. educators and the collaboration regime between the spheres of government.
\end{abstract}

Keywords: Youth and adult education. Educational planning. Educational policies.

\title{
1. INTRODUÇÃ̃O
}

O caminho que leva à construção do novo plano plurianual de educação passa pelo diagnóstico da situação atual e por uma visão dos desafios futuros, mas exige também um olhar retrospectivo sobre o percurso de formulação e implementação do plano anterior, para avaliar o alcance das metas então fixadas e compreender os fatores que incidiram sobre os resultados alcançados. Essa revisão é especialmente necessária quando está em tela a EJA, âmbito em que é flagrante o insucesso das políticas públicas frente à meta de superação do analfabetismo, mencionada na Constituição Federal e nos compromissos assumidos pelo país em fóruns internacionais.

Dias d'Ávila é um município brasileiro do estado da Bahia. Em 2020 a sua população estimada era de 82432 habitantes. No mesmo se encontra as melhores fontes de água da Bahia, fato que lhe dá o apelido de "Cidade das Águas". Pertencente a RMS (Região metropolitana de Salvador), e vizinha ao Pólo industrial de Camaçari, a cidade é habitada por uma grande massa de trabalhadores que se mudaram para lá após a implantação e ampliação do Pólo petroquímico de Camaçari (cidade vizinha).

Antigamente a cidade era considerada umas das melhores cidades de veraneio, pelas suas paisagens e clima agradável, além do seu principal ponto turístico: o Imbassay, localizado pós nascente de um rio, a lama presente era considerado por muitos como medicinal.

Hoje, a cidade passa-se como cidade dormitório, com sua maioria de origem externa, até pelo fato da cidade ter apenas 30 anos desde a sua emancipação política de Camaçari, emancipação esta que até hoje é criticada devido aos limites territoriais estabelecidos para a cidade, que limitou o seu desenvolvimento.

\section{REFERENCIAL TEÓRICO}

2.1 Educação de Jovens e Adultos

A educação de jovens e adulto, EJA, é uma modalidade do ensino fundamental e do ensino médio, que possibilita a oportunidade para muitas pessoas que não tiveram acesso ao conhecimento científico em idade própria dando oportunidade para jovens e adultos iniciar e /ou dar continuidade aos seus estudos, é portanto uma modalidade de ensino que visa garantir um direito aqueles que foram excluídos dos bancos escolares ou que não tiveram oportunidade de acessálos.

Existem diversos fatores que muitas vezes não possibilitam a alfabetização no período da infância no decorrer dos anos, o indivíduo sente a necessidade de inserir-se nesse processo e procura a EJA (Educação de Jovens e Adultos) oferecido por escolas públicas.

Em termos de acesso a essa modalidade, a legislação educacional define que a idade mínima para o ingresso nos cursos de educação de jovens e adultos e a participação nos exames supletivos é de 15 anos completos para o ensino fundamental e de 18 para o ensino médio. Conforme a constituição federal de 1988, no seu artigo 208 "o dever do estado com a educação será efetivado mediante a garantia de: Ensino fundamental obrigatório e gratuito para todos aqueles que não tiveram acesso na idade própria (...)”. 
A educação é essencial ao ser humano, principalmente nos dias de hoje, em que se depara com um ambiente de competitividade, diversos documentos assim como a Lei de Diretrizes e Bases vista anteriormente, tal afirmação se confirma. No presente século com todas as inovações tecnológicas, e com a grande modernização econômica e cultural, ainda se enfrenta um grande problema que impede o desenvolvimento do país, consequência da falta de investimento na educação, o que gera a má qualidade da mesma, causa assim o desânimo de todos, seja do docente e até mesmo do próprio educando, refletido através da evasão, e baixos salários, e torna a educação de má qualidade.

Onde se investe em educação é notória a contribuição do crescimento econômico do desenvolvimento social e cultural da sociedade e país.

\subsection{Plano Municipal de Educação 2015 - 2024 de Dias D’áVILA (BA)}

O objetivo deste trabalho é compreender as políticas públicas para a Educação de Jovens caracterização e estruturação da educação de jovens e adultos no plano municipal de educação 2015 - 2024 de Dias D’ávila (BA)no período de 2012 a 2015 . Tratou-se de uma revisão de literatura de caráter bibliográfico descritivo. Gil (2004, p.137) descreve a revisão de literatura como sendo uma ação sobre material já produzido.

As publicações encontradas foram ordenadas como pesquisa e de revisão e, posteriormente, categorizadas. Historicamente a Educação de Adultos foi marcada pelo objetivo de erradicar o analfabetismo, que era visto como causa e não como efeito da situação econômica, social e cultural do país.

Analisa ainda abordagem conferida à EJA nos documentos preparatório e final da Conferência Nacional de Educação (CONAE) e indica desafios prioritários desse campo educativo a serem enfrentados pelo novo PNE 2011-2020 nos âmbitos das concepções políticopedagógicas, do financiamento, da formação e profissionalização dos educadores e do regime de colaboração entre as esferas de governo.

\subsection{Diagnóstico do PME Acerca do EJA no Município de Dias D’ávila (Ba)}

O Plano Municipal de Educação de Dias D’Ávila se encontra em vigor desde o ano de 2015, e, que estabelece suas metas a serem cumpridas até o ano de 2025. O referido documento que possui como foco suprir as necessidades educacionais do município está divido em 220 estratégias de ação para o cumprimento de 20 metas que abordam todos os níveis e aspectos da educação, em seus mais diversos níveis de escolaridade (da educação infantil e do ensino fundamental até o ensino médio, superior, tecnológico, especial e tempo integral) e em aspectos de gestão escolar, carreira dos profissionais da secretaria e financiamento de programas e projetos de complementação. (DIAS D’ÁVILA, 2015).

De acordo com Dias D’Ávila (2015), tais estratégias foram discutidas e culminadas em dois momentos centrais: na Conferência Municipal da Educação (sem data ou mais informações disponibilizadas no documento), e em Audiência Pública, que dentro de um processo de participação democrática, teceram críticas, sugestões e ajustes que auxiliaram na construção final deste PME, que levou em consideração os aspectos históricos, geográficos, demográficos, socioeconômicos e culturais, para estabelecer um perfil da população que se pretende atender.

Pelas informações dispostas no documento, no que se refere a Educação de Jovens e Adultos, podemos destacar três principais levantamentos: primeiramente os índices de disparidade idade/série, os índices de analfabetismo e por fim os índices de evasão.

O capítulo dedicado à EJA no PNE aprovado pelo Congresso na forma da Lei n. 10.172/2001 teceu um diagnóstico que reconheceu a extensão do analfabetismo absoluto e funcional e sua desigual distribuição entre as zonas rural e urbana, as regiões brasileiras, os grupos de idade, sexo e etnia. O Plano admitia ser insuficiente apostar na dinâmica demográfica e atuar apenas junto às novas gerações, propondo que as ações de escolarização atingissem também os adultos e idosos.

Nas diretrizes, o PNE aderiu à concepção de educação continuada ao longo da vida, mas priorizou a atenção ao direito público subjetivo dos jovens e adultos ao ensino fundamental público e gratuito.

O capítulo sobre EJA enunciou 26 metas, dentre as quais se destacavam cinco objetivos: 1) alfabetizar, em cinco anos, dez milhões de pessoas, de modo a erradicar o analfabetismo em uma década; 2) assegurar, em cinco anos, a oferta do primeiro ciclo do ensino 
fundamental a metade da população jovem e adulta que não tenha atingido esse nível de escolaridade; 3) oferecer, até o final da década, cursos do segundo ciclo do ensino fundamental para toda a população de 15 anos ou mais que concluiu as séries iniciais; 4) dobrar, em cinco anos, e quadruplicar, em dez anos, a capacidade de atendimento nos cursos de EJA de nível médio; 5) implantar ensino básico e profissionalizante em todas as unidades prisionais e estabelecimentos que atendem a adolescentes infratores.

2.4 Índices de Disparidade Idade/Série

A frequência escolar da população infantojuvenil, entre 7 e 15 anos de idade, não é mais um desafio para as autoridades governamentais brasileiras. Em 2008, segundo dados da PNAD, mais de 90\% de nossas crianças e adolescentes frequentavam a escola. Contudo, a defasagem série-idade ainda permanece como desafio. São considerados em situação de defasagem escolar os alunos que não possuírem no início de cada ano letivo os anos de estudo compatíveis com a sua idade.

No mesmo ano de 2008, variava entre $2 \%$ e $22 \%$ o índice de crianças com 7 e 8 anos de idade que estavam com atraso escolar, enquanto entre os jovens de 15 anos essa proporção atingia $46 \%$. Em geral, os determinantes da defasagem idade-série são: entrada tardia na escola, evasão ou repetência escolar.

Para a elaboração de políticas públicas educacionais é fundamental o entendimento dos determinantes dos principais fatores que contribuem para defasagem escolar. Neste artigo nos concentramos na defasagem escolar na medida em que esse indicador pode ser considerado uma variável síntese de outros indicadores. Dessa maneira, a melhora na defasagem escolar expressa em alguma medida uma mudança em outros indicadores como entrada tardia na escola, repetência ou evasão escolar.

O fenômeno da defasagem escolar não pode ser reduzido às variáveis socioeconômica das famílias já que a quantidade e a qualidade das escolas, o ingresso no mercado do trabalho, as características individuais observáveis e não observáveis são também determinantes importantes. Contudo, no presente estudo nos concentramos nos determinantes vinculados aos recursos familiares tal como apontados pela teoria econômica convencional e a sociologia da educação. De acordo com Coleman (1993), as variáveis associadas às famílias exercem papel relevante nos indicadores educacionais.

A principal contribuição deste artigo se refere ao esforço de interpretar os principais pontos de convergência e divergência entre os teóricos do capital humano, os reprodutivistas e aqueles defensores da ação racional. A partir dessa reflexão podemos apontar os limites e alcances do Programa Bolsa Família que tem como objetivo a superação da pobreza no longo prazo por meio da elevação do nível de escolaridade.

2.5 Os Índices de Analfabetismo

A análise dos níveis de analfabetismo e letramento com base nos censos requer se esclareça a especificidade dos censos demográficos nas dimensões do tipo de fonte e da unidade de análise. Sob o aspecto demográfico, as populações humanas podem ser analisadas de dois pontos de vista distintos e complementares: o de seu estado ou situação e o de seu movimento ou dinâmica.

Esses dois tipos de estudos se socorrem de dois tipos básicos de fontes e de estatísticas. Os censos lidam com informações relativas ao estado da população. Na mesma linha situam-se as diversas pesquisas por amostragem, conduzidas periodicamente pelo IBGE, como as PNADs (Pesquisa Nacional por Amostragem de Domicílio).

Já as informações/estatísticas do movimento da população são obtidas principalmente por meio dos registros civis (de nascimentos, mortes, casamentos/separações/ divórcios). Tal divisão não é exclusiva. Os recenseamentos, por exemplo, complementam as informações dos registros sobre o movimento natural da população, além de se constituírem em fonte importante para o estudo dos movimentos migratórios. 


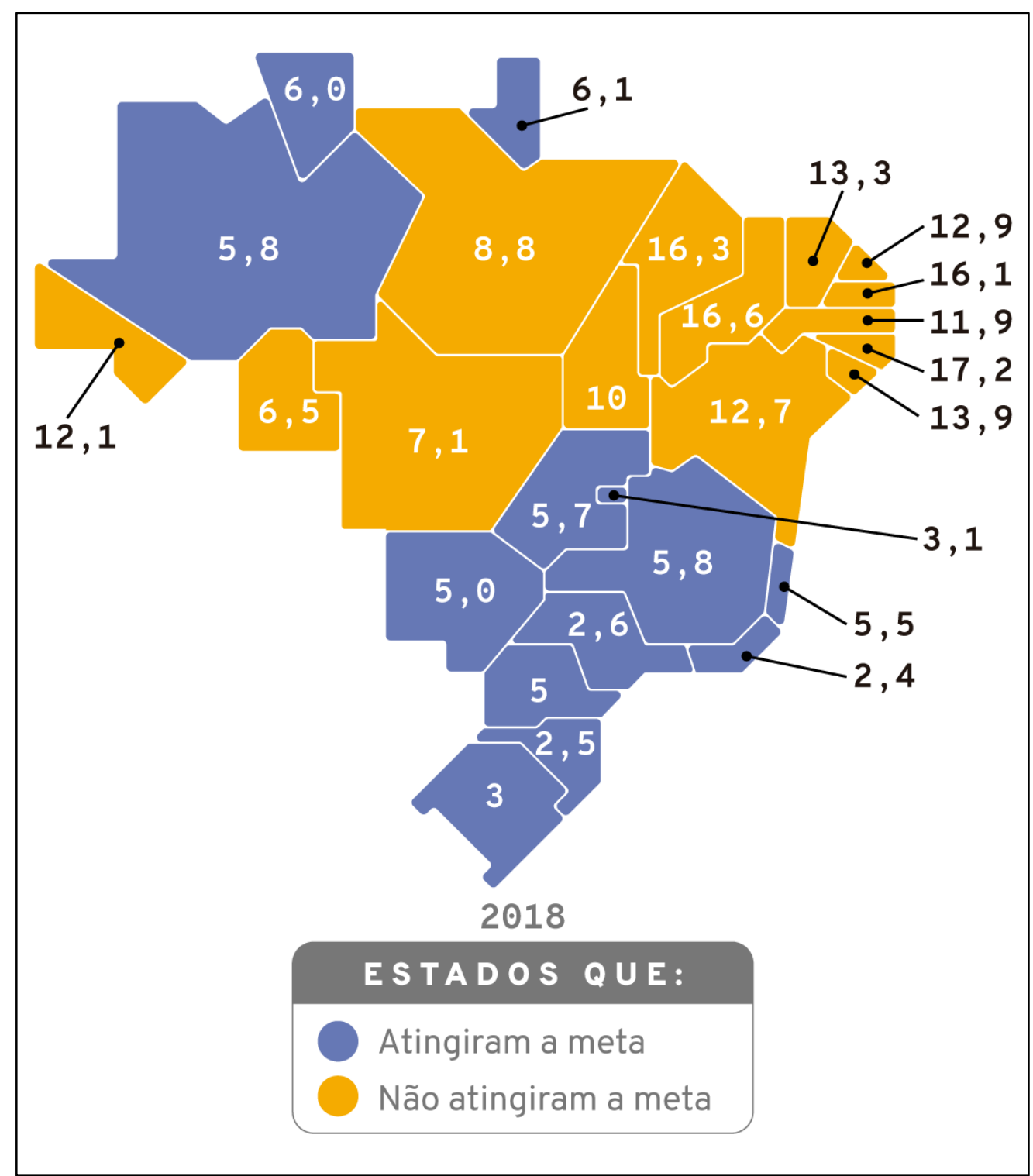

Fonte : Ministério da Educação (2019)

Há, além disso, outras fontes complementares de estatísticas demográficas do estado da população, como os inquéritos exaustivos sobre conjuntos populacionais reduzidos, as pesquisas nacionais e regionais por amostragem, e os inquéritos retrospectivos por meio de arquivos.

Figura 2 - Analfabetismo no Brasil

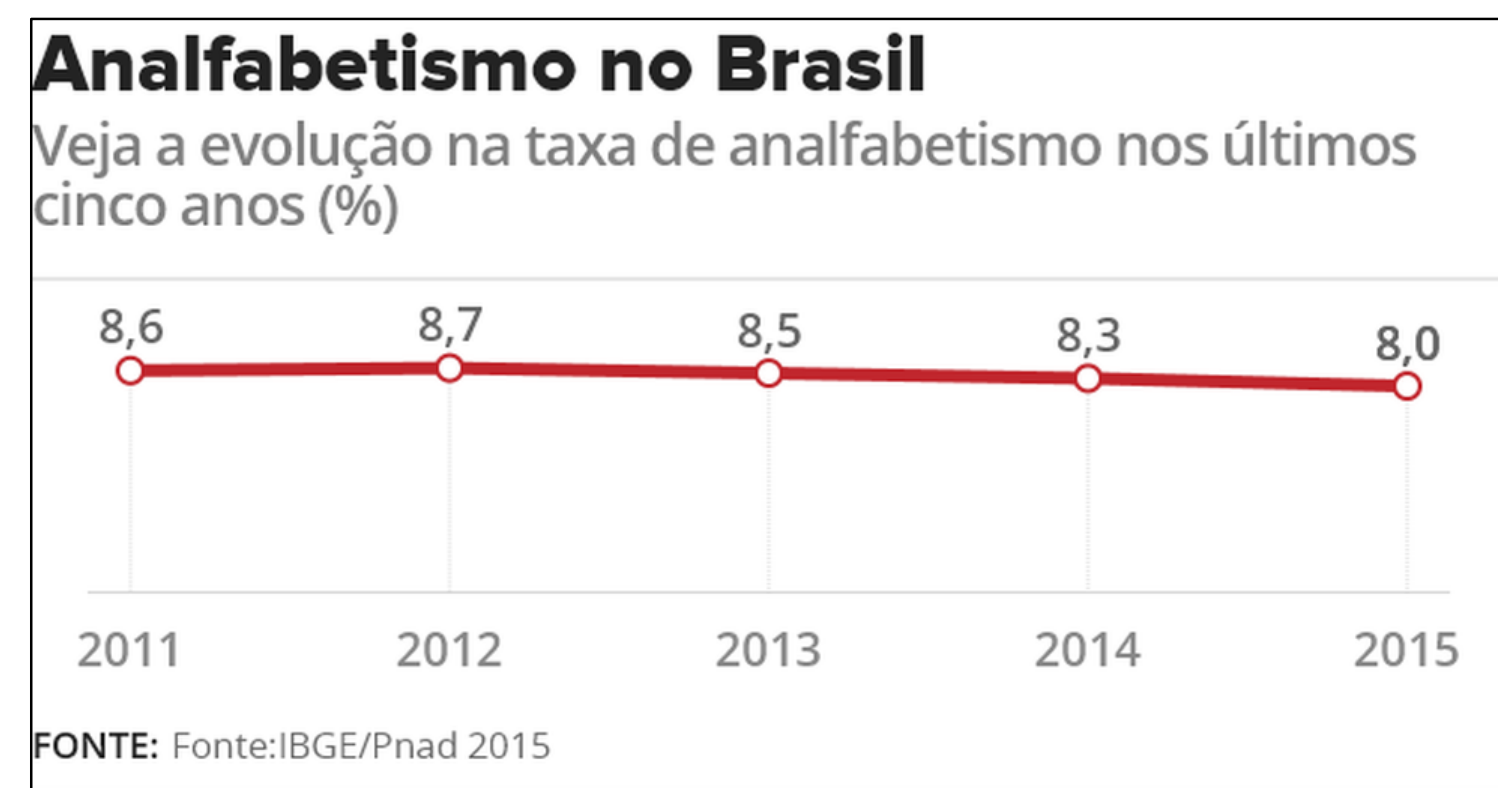

I1 Infográfico elaborado em: 24/11/2016

Fonte: Portal G1

De maneira semelhante, os registros também contêm subsídios para se apurar determinadas características da população ou pelo menos de determinados conjuntos populacionais. Por exemplo, dos pais, dos nubentes, dos falecidos. 
Figura 3 - Evolução das taxas de analfabetismo por região

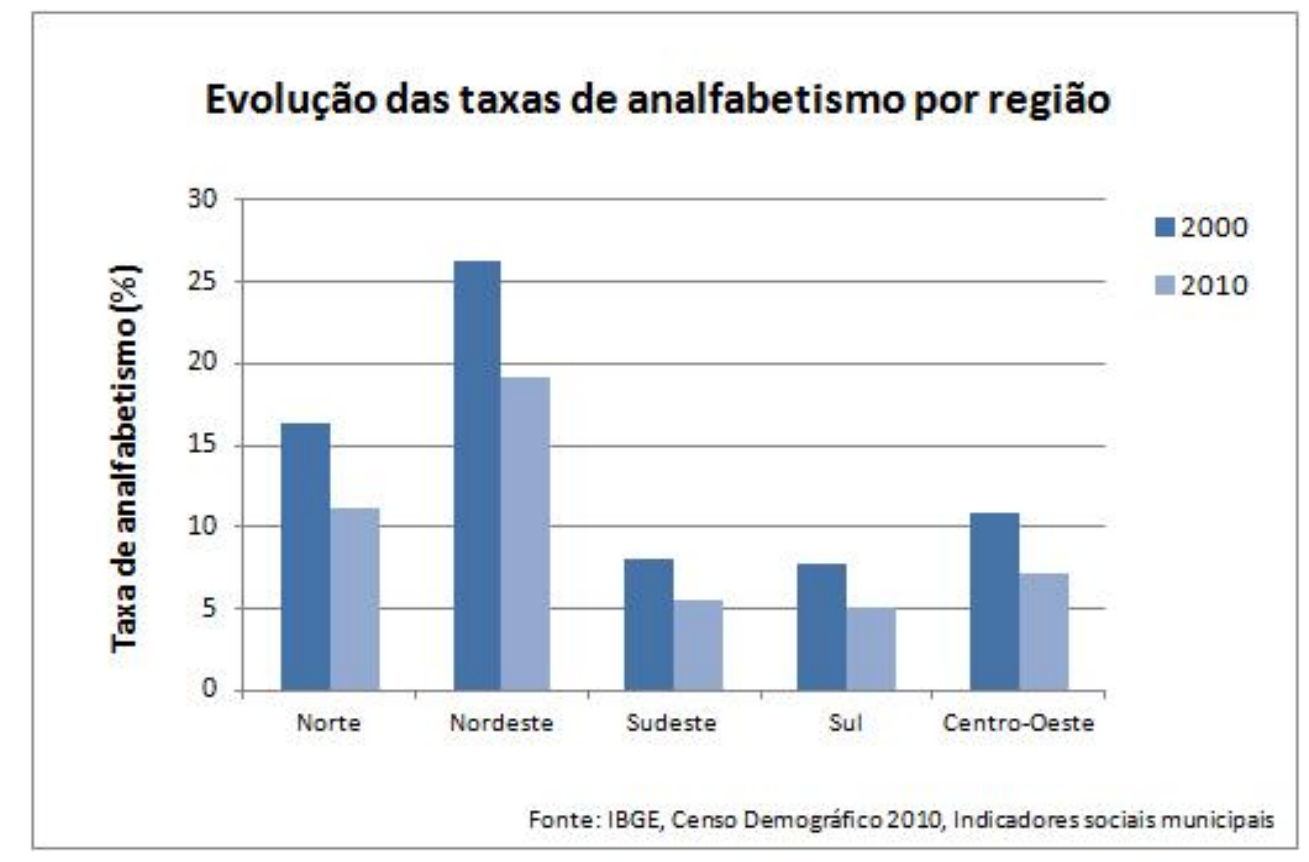

Fonte: Portal G1

Mas, na perspectiva do presente estudo, interessa firmar a distinção entre os dois tipos básicos de fontes - os censos e os registros civis, e os correspondentes tipos de informação produzida -, estatísticas do estado e estatísticas do movimento da população.

2.6 Índices de Evasão Escolar

De acordo com Bahia (2006), as turmas noturnas de Educação de Jovens e Adultos (EJA) tinham em escala estadual, na Bahia, uma taxa de abandono escolar de 40\% no Ensino Fundamental e uma média de 10 à $30 \%$ no Ensino Médio o que segundo o Plano Estadual de Educação, demostrava na época a baixa produtividade do sistema escolar baiano e principalmente a sua incapacidade em proporcionar a permanência dos alunos na escola.

Segundo Dias D’Ávila (2015), o município em 2015 possuía vinte e duas escolas, dos quais somente seis delas possuíam oferta de matrícula para estudantes da modalidade EJA para o ensino fundamental, sendo a maioria delas direcionadas para oferta de ensino no turno noturno.

A situação se torna um pouco preocupante na zona rural do município onde das cinco escolas existentes em 2013, somente três ofereceram turmas de supletivo para o ensino fundamental primário, e em 2014, nenhuma escola do núcleo rural funcionou a noite com a educação de jovens e adultos. Entretanto, ainda segundo o PME, as unidades e o número de atendimento para estudantes de EJA tem reduzido graças aos altos índices de evasão.

A evasão é o terceiro tópico elencado no Plano Municipal de Educação para estabelecer um parâmetro da educação na cidade. Utilizando os dados de 2012 a 2014 podemos observar a gravidade do problema.

A evasão escolar na EJA, como vemos, tem sido talvez o maior problema enfrentado pelas unidades de ensino, não é incomum que o número de alunos evadidos em cada sala seja maior que o número de alunos aprovados, o que ocasiona no fechamento de muitas classes. Como podemos observar nas Tabelas 3 e 4, as taxas de evasão nas turmas de EJA do ensino fundamental compreendem, em sua maioria quase metade dos alunos matriculados.

2.7 Diagnóstico do Andamento da Execução das Metas Para EJA No PME de Dias D’ávila (Ba) 
Sabe-se que este trabalho se guia ao seu objetivo por uma metodologia de análise de estudo de caso. Como bem nos evidencia Meirinhos e Osório (2016), a principal vantagem de tal método de pesquisa é a sua aplicabilidade a situações e contextos humanos de vida real. Ainda segundo os autores, deve-se ter uma atenção particular para não cometer generalizações acerca de contextos semelhantes, entretanto é uma forma de compreender as causas e efeitos de um cenário por ele mesmo.

Autores como Gillham (2000) concordaram com a capacidade dos estudos de caso em construir teorias a partir da experiência de recolhimento das informações, já que nestas investigações a teoria não vem em primeiro lugar, mas sim a evidência, pois até que se tenham dados para compreender o contexto, não são levantadas explicações para responder o problema que motivou a pesquisa.

Podendo um estudo de caso ter principalmente três estilos: exploratórios, descritivos e explanatórios, este terceiro se mostra como o mais notável dos métodos para nossa proposta final, a ser desenvolvida no terceiro capitulo, pois não se limita apenas a exposição do problema investigado, mas procura informações que possam estar correlacionadas que "possibilite o estabelecimento de relações de causaefeito, ou seja, procuram a causa que melhor explica o fenómeno estudado e todas as suas relações causais" (MEIRINHOS; OSÓRIO 2016, p. 57). Entretanto, neste momento, nos limitamos a estudo descritivo do estágio de realização das metas para a Educação de Jovens e Adultos (EJA) no Plano Municipal de Educação (PME) de Dias D’Ávila. Antes de fazermos possíveis horizontes interpretativos para a evasão, faz-se necessário verificarmos a eficácia da aplicação dos planos públicos na tentativa de solucionar tais problemas.

Como já mencionado, o Plano Municipal de Educação de Dias D’Ávila possui 20 metas, subdividas em 220 estratégias para corrigir as deficiências que se encontram em todos os aspectos da educação no município. Neste documento, apesar de apenas duas metas (a de número 9 e 10) serem direcionadas as melhorias e avanços da educação de jovens e adultos, juntas elas somam o total de 19 objetivos (14 da meta nove, e 5 da meta 10) a serem alcançados para considerar efetivamente realizadas as finalidades do PME. As estratégias da meta 10, entretanto, não serão aqui debatidas, pois apresentam total inexistência.

Tais delimitações são importantes, pois deixam claro e objetivam as finalidades e horizontes a qual as ações da secretaria de educação devem visar em suas atividades. O problema como pode observar é que tais realizações mesmo bem delimitadas no documento ainda não chegam perto de lograr êxito, como podemos observar logo abaixo nas estratégias da meta número nove, que pretendia “Implantar politica de melhoria das condições de acesso, permanência e sucesso na EJA, até 2020.” (DIAS D’ÁVILA, 2015, p. 128).

Segundo Dias D’Ávila (2015, p. 129), em suas três primeiras metas, era desejo do município “Aumentar, progressivamente, a oferta de educação de jovens e adultos, de forma que o município atenda $90 \%$ dos jovens e adultos [...] reduzir em 70\%, o índice de analfabetismo no município. [e] reduzir a taxa de abandono dos estudantes matriculados na EJA em 30\%”. Como podemos observar, tais metas não lograram êxito, a percepção dos docentes da rede é de que não apenas reduziu o acesso, mas também reduziu a permanência.

Pode-se destacar como exemplo a Escola Drummond de Andrade, que mesmo sendo a maior escola do município, não chega a atender 500 alunos em todas as turmas de EJA do fundamental inteiro.

Um fato que vale a pena se destacar é a aposta das instituições na evasão. Já prevendo os altos índices de desistência, costuma-se matricular até 60 alunos em uma única turma, atitude esta que vai contra as recomendações do Conselho Nacional de Educação que sugere em turma do "Ensino Fundamental: anos iniciais: 24 alunos" e para os anos finais um apenas "30 alunos" (BRASIL, 2010, p. 19)

Acredita-se que matriculando muito acima do número limite, após a evasão a turma se encontrará com o número adequado de alunos. Os quartos tópicos da meta nove esperavam que neste ano vigente de 2020 a rede municipal pudesse "oferecer, no turno diurno, 20\% do total de vagas disponibilizada para a EJA, atendendo também, a comunidade do campo.”. (DIAS D’ÁVILA, 2015, p. 129). Aqui, mais uma vez, vemos discrepância entre o planejado e o realizado.

\section{METODOLOGIA}

3.1 Tipo de estudo

Tratou-se de uma revisão de literatura de caráter bibliográfico descritivo. Gil (2004, p.137) descreve a revisão de literatura como sendo uma ação sobre material já produzido. As publicações encontradas foram ordenadas como pesquisa e de revisão e, posteriormente, categorizadas.

A revisão bibliográfica foi feita mediante análise acurada da literatura aplicada, retirando-se os pontos pertinentes ao tema aclarado, com o fim de justificar as ações apresentadas.

A Pesquisa bibliográfica, para Martins (2001, p.32), "procura explicar e discutir um tema com base em referências teóricas publicadas em revistas, livros, periódicos e outros. Procura também, conhecer e analisar conteúdos científicos sobre determinado tema".

Quanto ao tipo de abordagem da pesquisa, será aplicado o método qualitativo. De acordo com Gil (1994), a importância da investigação científica a partir de análises bibliográficas reside no fato de que o pesquisador pode obter uma ampla gama de conceituações e problematizações a cerca de um determinado tema, levando em consideração a avaliação de dados relevantes produzidos pela ciência. 
Segundo Gerhardt e Silveira (2009, p.32), "explora o universo de significados e valores, entre os quais, podemos destacar: motivos, aspirações, crenças, atitudes, entre outros”. Essas variáveis correspondem a um significado profundo das relações, dos processos e dos fenômenos a serem analisados, não permitindo que sua utilização seja reduzida ao uso de variáveis. É um dos métodos de pesquisa bastante utilizados em investigações na área educacional (FERREIRO, 1999).

A pesquisa está direcionada para um maior conhecimento acerca da atuação docente no processo de ensino e aprendizagem no ensino fundamental, e analisar os problemas sociais, e culturais que afetam o processo de desenvolvimento do estudante, serão os quesitos principais para produção deste trabalho.

3.2 Fontes de estudo

Para a realização da pesquisa elegeu-se como fonte as seguintes obras: Antunes (2003), Cagliari (1999), Freire (2003), Soares (2005), Kleiman (2006), Bakhtin (1979), bem como os Parâmetros Nacionais de língua Portuguesa (2001), dentre outros. 42 Realizou-se a leitura dos textos sobre o assunto, a partir das seguintes categorias: paradigmas de Leitura e Escrita, Alfabetização, Ensino, Aprendizagem.

3.3. Análise das fontes

Após o acesso às fontes fez-se a leitura de todo o material, compilando-se as informações principais, em categorias de análise. Em seguida, realizou-se de forma descritiva uma análise dos referidos materiais, visando estabelecer uma compreensão e ampliação do conhecimento sobre o tema pesquisado.

\section{REFERÊNCIAS BIBLIOGRÁFICAS}

BOURDIEU. P. (1999a). "A escola conservadora: as desigualdades frente à escola". In: NOGUEIRA, M.A.; CATANI, A. (Org.). Escritos de Educação. Petropólis: Vozes: 39-64.

BOURDIEU. P. (1999b). "O capital social - notas introdutórias". In: NOGUEIRA, M.A.; CATANI, A. (Org.). Escritos de Educação. Petropólis: Vozes, 1999b: 65-70.

BOURDIEU. P. (1999c). "Os três estados do capital cultura". In: NOGUEIRA, M.A.; CATANI, A. (Org.). Escritos de Educação. Petropólis: Vozes: 71-80.

BOURDIEU, P.; PASSERON, J.C. (1975). A Reprodução: Elementos para uma Teoria do Sistema de Ensino. Rio de Janeiro: Francisco Alves, 1975.

BOWLES, S; GINTIS, H. (1976). Schooling in Capitalism America. New York: Basic Books.

COLEMAN, J. S.(1993). Equality and Achievement in Education. Boulder, CO: Westview Press.

DURYEA, S. (1998). Children's Advancement Trough School in Brazil: The Role of Transitory schoks to household income. Banco Interamericano de Desarrollo. Documento de Trabajo, 376.

HADDAD, S. A participação da sociedade civil brasileira na educação de jovens e adultos e na CONFINTEA VI. Revista Brasileira Educação, Rio de Janeiro, v. 14, n. 41, p. 355-369, ago. 2009.

HADDAD, S.; DI PIERRO, M.C. An historical overview of adult formal education in Brazil. In: CASTRO, R.V.; SANCHO, A.V.; GUIMARÃES, P. (Ed.). Adult education: new routes in a new landscape. Braga: Universidade do Minho, 2006. p. 231-270.

MONLEVADE, J. Plano Nacional de Educação ou carta de intenções? Cadernos do Observatório, Rio de Janeiro, n. 3, p. 17-31, dez. 2001.

PAIVA, J.; MACHADO, M.M.; IRELAND, T. (Org.). Educação de jovens e adultos: uma memória contemporânea (1996-2004). Brasília, DF: UNESCO/MEC, 2004. 